\title{
The Effect of Psychosocial Factors and Patients' Perception of Tuberculosis Treatment Non-Adherence in Addis Ababa, Ethiopia
}

\author{
Habteyes Hailu Tola ${ }^{1,2} *$, Gholamreza Garmaroudi ${ }^{1}$, Davoud Shojaeizadeh ${ }^{1}$, \\ Azar Tol ${ }^{1}$, Mir Saeed Yekaninejad ${ }^{3}$, Luche Tadesse Ejeta ${ }^{1}$, Abebaw Kebede ${ }^{2}$, \\ Desta Kassa $^{2}$
}

\footnotetext{
OPEN ACCESS

Citation: Habteyes Hailu Tola,

Gholamreza Garmaroudi Davoud Shojaeizadeh, Azar Tola, et al. The Effect of Psychosocial Factors and Patients' Perception of Tuberculosis Treatment Non-Adherence in Addis Ababa, Ethiopia. Ethiop J Health Sci.2017;27(5):447.

ddoi:http://dx.doi.org/10.4314/ejhs.v27i 5.2

Received: February 28, 2017

Accepted: March 1, 2017

Published: September 1, 2017

Copyright: () 2017 Habteyes Hailu. This is an open access article distributed under the terms of the Creative Commons Attribution License, which permits unrestricted use, distribution, and reproduction in any medium, provided the original author and source are credited.

Funding: Family Guidance Association of Ethiopia

Competing Interests: The authors

declare that this manuscript was approved by all authors in its formand that no

competing interest exists.

Affiliation and Correspondence:

${ }^{1}$ Department of Health Education and Promotion, School of Public Health,

Tehran University of Medical Sciences-International Campus,

Tehran, Iran

${ }^{2}$ TB/HIV Research Directorate, Ethiopian Public Health Institute, Addis Ababa, Ethiopia

${ }^{3}$ Department of Epidemiology and Biostatistics, School of Public Health,

Tehran University of Medical

Sciences, Tehran, Iran

*Email: habtetola@gmail.com
}

\section{ABSTRACT}

BACKGROUND: Although there are several studies reported on factors affecting tuberculosis (TB) treatment non-adherence, there is information gap on psychosocial and patients' perceptions aspects. Therefore, this study was aimed to investigate the effect of psychosocial factors and patients' perceptions on TB treatment non-adherence in Ethiopia.

METHODS: A cross sectional study was conducted in Addis Ababa from May to December, 2014. Thirty one health facilities were randomly selected and $698 \mathrm{~TB}$ patients, who had been on treatment, were enrolled consecutively using patient registration number. Structured questionnaire was used to collect data on demographics, knowledge, psychological distress, alcohol use, tobacco smoking and six HBM domains. Treatment adherence level was the main outcome variable, and it measured using visual analog scale. Statistical Package for Social Sciences version 20 was used for data analysis.

RESULTS: Non-adherence level within last one month prior to the study was $19.5 \%$. After controlling for all potential confounding variables, Antiretroviral Therapy (ART) status (Adjusted Odds Ratio $(A O R)=1.79$, 95\% Confidence interval $(C I)(1.09-2.95)$ ), alcohol use $(A O R=2.11,95 \%$ CI (1.33-3.37)), economic status $(A O R=0.53,95 \% C I(0.33-0.82))$, perceived barriers $(A O R=$ 1.21, 95\% CI (1.10-1.47)) and psychological distress $(A O R=$ 1.83, 95\% CI (1.47-2.29)) were independently associated with TB treatment non-adherence.

CONCLUSION: ART status, economic status, alcohol use, perceived barrier and psychological distress are the major areas that need to be targeted with health promotion intervention to enhance TB treatment adherence.

KEYWORDS: Treatment Non-adherence, Determinants of treatment non-adherence, Health Belief Model, Tuberculosis 


\section{INTRODUCTION}

Non-adherence to long term treatment is one of the major problems, which leads to poor treatment outcome due to its high risk of treatment failure and long term disease transmission $(1,2)$. For instance, if we take the effect of drug resistance, the emergence of drug-resistance microbes is posing challenges to prevention and control programs of Tuberculosis (TB) (2-4). TB treatment non-adherence can also results in the occurrence of Multidrug Resistance, Extensively Drug Resistant TB (MDR-TB and XDR-TB) bacilli (3). According to WHO report, $3.6 \%$ and $20.2 \%$ of MDR-TB cases were registered among new and previously treated cases respectively in 2013 (5).

Apart from treatment failure and the occurrence of MDR-TB, treatment nonadherence has several socioeconomic impacts (6$8)$. For example, it can increase duration of treatment (6) and hospital bed occupancy rate (6$8)$, economic depletion and dependency (8), and induction of mental illness (7).

Treatment adherence is a complex phenomenon that is influenced by a wide range of interacting factors $(7,9)$. Depression and anxiety, individual negative emotional status $(10,11)$ and fear of stigma (12), general disease and its treatment knowledge (12-17), patients' perception of the disease and its treatment (18-20), lack of social support, and economic hardships are associated with TB treatment non-adherence $(12,15-17,21)$. Moreover, poorly oriented health services, poor medication distribution, poor communication and others are factors related to health care workers and the health system itself in respect to TB treatment adherence $(16,17,22,23)$. On the other hand, studies show that alcohol consumption and tobacco smoking history $(16,17,24-26)$ and patients' HIV and Antiretroviral (ART) status are associated with TB treatment non-adherence $(21,27)$.

Although previous studies reported several determinants of TB treatment nonadherence, few of them assessed the effect of psychosocial factors and individual patient's perception on TB treatment non-adherence. Moreover, though it is recommended to use social and behavioural science theoretical models to generate strong evidence on health promotion including treatment adherence $(9,28,29)$ few studies have so far applied theoretical models to assess determinant factors of TB treatment non-adherence.

In Ethiopia, few studies have been conducted to assess determinant factors of TB treatment non-adherence, and based on these studies, the proportion of non-adherence rages from $10 \%$ to $21 \%(13,14,27)$. Apart from scarcity of information in Ethiopia, there is no study conducted based on theoretical models to determine psychosocial factors and individual patient's perception that influence TB treatment non-adherence. In addition, although previous studies conducted in Ethiopia reported numerous determinants of TB treatment non-adherence, none of them reported the effect of psychosocial factors and individual patient's perception based on theoretical model $(13,14,22,27)$. Therefore, this study was aimed to determine the effect of psychosocial and individual patient's perception on TB treatment non-adherence based on Health Belief Model (HBM) in Ethiopian.

HBM is the most widely used and important model to understand and explain health behaviors including treatment adherence as a healthy practice $(30,31)$. However, it is being criticized for focusing on individual characteristics and cognitive factors, giving less attention to social influences and emotional components of behavior. This theoretical model consists of six domains in its recent version (29). These are perceived susceptibility, perceived severity, perceived benefits, perceived barriers, cue to action and perceived self-efficacy (29). According to HBM concept, TB patients with a given sociodemographic characteristics and mental health status are likely to follow their medicinal regimen correctly under a specific five sets of conditions $(31,32)$. These are:

1. TB patients must have some minimal knowledge on their illness and motivation to be free of TB; 
2. TB patients must perceive themselves as susceptible to TB and must also believe that TB disease and consequences of nonadherence can cause serious medical and health problems;

3. TB patients must also be influenced by the effectiveness of TB treatment, which could result in the possibility to obtain control over the tangible and psychological barriers at acceptable level;

4. The presence of an internal or external stimulus, referred as "cue to action," is a trigger of adherence behavior of TB patients'; and

5. TB patients' trust in self-ability to strictly follow the treatment till the final dose. Based on the HBM theoretical concepts mentioned above, this study applied the model to determine the effect of psychosocial factors and individual patient's perception on TB treatment adherence.

\section{METHODS}

Study design and setting: A cross sectional study was conducted to determine the effect of psychosocial factors and individual patient's perception on TB treatment non-adherence in Addis Ababa from May to December, 2014. Addis Ababa consists of 10 sub-cities with an estimated total population 2,975,608 (33). In addition, it consists of 53 health centers and 10 public hospitals (34). All diagnosed TB patients are treated under Directly Observed Treatment (DOT) strategy (35).

Study population and sampling: The study population was all types of TB patients who were on first line and MDR-TB treatment regimens under Directly Observed Treatment Short course (DOTS) strategy in randomly selected 30 Health Centers (HCs) and one purposively selected TB specialized hospital in Addis Ababa. Thirty HCs were selected using simple random sampling technique from $53 \mathrm{HCs}$, located in the city. The number of HCs (clusters) selected was set at 30 based on WHO recommendation regarding minimum number of survey clusters (36). From selected study sites, 698 TB patients, who had been on treatment for one month and above, older than 17 years and living in Addis Ababa for more than six months were enrolled consecutively from TB registration book using patients' identification numbers. However, severely sick and mentally incapable patients were excluded. Consecutive enrollment of participants from registration book was used to achieve the maximum sample size and to avoid selection bias.

Data collection instrument and procedure: A structured questionnaire was used to collect sociodemographic data. Economic status was assessed with 10 structured questions which ask ownership position of basic assets. The response of each question was recorded by yes $=1$ and no $=$ 0 . To estimate the total score of economic status, one dimension Categorical Principal Component Analysis (CPCA) technique was used. Thirty eight structured items were employed to collect TB disease and its treatment related knowledge. The responses to each knowledge question were recorded on three level Likert's scale such as "correct", "incorrect" and "don't know". One point was given for each correct answer (correct response score $=1$ ) and zero for incorrect and don't know responses (incorrect and don't know responses score $=0)$ (Table 1). The total knowledge score was calculated using total sum method. In addition, a total of 76 structured items were designed based on literature review and the concept of HMB to collect information on six HBM domains. The degree with which each of these items expressed was recorded using a five-point Likert's scale ranging from "strongly disagree" with lower score (1) to "strongly agree" with higher score (5) (Table 1). Total perception score of each HBM domain was estimated by CPCA. To show frequency distribution of nonadherence level with respect to knowledge and perception levels, total knowledge score and total HBM domains scores were dichotomized using median score of each variable as a cut-off point. However, in the logistic regression modeling, continuous scores of knowledge and HBM domains were used (Table 4). To assess the presence of psychological distress symptoms characterized by depression and anxiety in the last one month, Kessler-10 items (K-10) scale was

DOI: http://dx.doi.org/10.4314/ejhs.v27i5.2 
used $(37,38)$. The frequency with which each of these items experienced was recorded using a five-point Likert's scale ranging from "none of the time" with lower score to "all the time" with higher score (Table 1). The total psychological distress score was estimated by CPCA. This scale has been largely used to assess common mental disorders (CMDs) among TB patients, and has been validated in several settings (39) including in Ethiopia (40). WHO Alcohol Use Disorder Identification Test (AUDIT) 10 items was used to assess alcohol use history (41), while tobacco smoking history was collected using Australian Smoking Assessment Check list (42). Information on TB patients' HIV and ART status was collected from participant self-report and rechecked from TB registration book. The questionnaire was validated prior to use for main study data collection by test and retest pilot study at selected study sites. Internal consistency of HBM domains and other variables were assessed using Cronbach's $\alpha$ analysis and the results were in acceptable range (0.70) (Table 1). Adherence level of patients was assessed by participant self report with Visual Analogues Scale (VAS) after carful explanation. In addition, participants who interrupted treatment due to medication adverse effect and lost to follow-up were interviewed through home visit after agreement was obtained through telephone call. VAS was scaled from $0 \%$ to $100 \%$ and re-coded to dichotomous variable (adherent or non-adherent) using 90\% cut-off point based on WHO adherence definition (4). WHO defines TB treatment non-adherent as "patients who did not attend a health facility at the scheduled visit and those who did not take regular medication above $90 \%$ of prescribed doses" (4). Therefore, in this study, non-adherent patients were: (1) those who scored their adherence level less than $90 \%$, (2) those who interrupted their treatment due to medication adverse effects, and (3) those who were lost to follow-up.

Data was collected by health professionals at each study site. Before data collection, a three days' training was offered to data collectors on how to administer the questionnaire. Data collectors were supervised during data collection on regular basis.

Data entry and analysis: Data was analyzed using Statistical Package for Social Science (SPSS) version 20. Proportions of non-adherence among participants' characteristics, knowledge score, six HBM domains scores and psychological distress score were determined to show the frequency distribution of treatment nonadherence. Before running multivariable logistic regression, bivariate analysis was conducted between each independent variable and nonadherence level. Variables with p-value less than 0.2 in bivariate analysis were included in multiple logistic regressions. However, although knowledge and the six HMB domains had p-value greater than 0.2 , they were included in the final model because they were the main exposure variables in the study and the main constructs of HBM model.

Ethical approval: This study protocol was ethically approved by Tehran University of Medical Sciences and the Ethiopian Public Health Institute Research Ethics Board. Both oral and written informed consent was obtained from each study participant.

\section{RESULTS}

Sociodemographic characteristics: A total of 698 all forms of TB [Pulmonary = 416(59.6\%)), Extra pulmonary $=215(30.8 \%)$, MDR-TB $=67(9.6 \%)]$ patients on treatment for one and above months were included in the study (Table 2). The age range of participants was 18-90 years, and about 457(65.5\%) participants were less than 35 years of age. More than half $(55.9 \%)$ of the participants were elementary school and below in terms of educational attainment, and $53.4 \%$ were unemployed and daily laborers (Table 2). About 29.3\% participants were migrants from rural areas to Addis Ababa and of these, $18.1 \%$ were daily laborers.

DOI: http://dx.doi.org/10.4314/ejhs.v27i5.2 
Table 1: Response score mean standard deviation and Cronbach's alpha of knowledge, psychological distress and each HBM domain.

\begin{tabular}{lccccc}
\hline Variable & No. Items & Scale & Mean score & Standard deviation & Cronbach's alpha \\
\hline Knowledge Score & 38 & $0-1$ & 30.5 & 4.7 & 0.85 \\
Perceived Susceptibility & 9 & $1-5$ & 28.2 & 6.6 & 0.78 \\
Perceived Severity & 9 & $1-5$ & 36.9 & 5.0 & 0.76 \\
Perceived Benefit & 8 & $1-5$ & 32.8 & 4.1 & 0.80 \\
Perceived Barrier & 31 & $1-5$ & 65.5 & 16.6 & 0.75 \\
Cue to action & 7 & $1-5$ & 31.7 & 5.3 & 0.77 \\
Perceived Self-efficacy & 12 & $1-5$ & 51.5 & 5.6 & 0.82 \\
Psychological distress & 10 & $1-5$ & 18.71 & 7.83 & 0.93 \\
Alcohol use disorder & 10 & $0-4$ & 3.5 & 2.7 & 0.90 \\
\hline
\end{tabular}

Table 2: Study Participants' Characteristics $(\mathrm{n}=698)$

\begin{tabular}{|c|c|c|c|}
\hline Variables & & Frequency & $95 \%$ CI of $\%$ \\
\hline \multirow{3}{*}{ Gender } & Female & 297 & $42.6(38.9-46.3)$ \\
\hline & Male & 401 & $57.4(53.8-61.1)$ \\
\hline & $18-24$ & 193 & $27.7(24.5-31.1)$ \\
\hline \multirow[t]{5}{*}{ Age Groups (in year) } & $25-34$ & 264 & $37.8(34.3-41.5)$ \\
\hline & $35-44$ & 136 & $19.5(16.7-22.6)$ \\
\hline & $45 \&$ above & 104 & $14.9(12.4-17.7)$ \\
\hline & Missing & 1 & $0.1(0.0-0.9)$ \\
\hline & Elementary \& less & 390 & $55.9(52.2-59.5)$ \\
\hline \multirow[t]{2}{*}{ Educational Status } & High School Graduate & 224 & $32.1(28.3-35.6)$ \\
\hline & Diploma \& Above & 84 & $12.0(9.8-14.7)$ \\
\hline \multirow[t]{3}{*}{ Marital Status } & Married & 224 & $32.1(28.7-35.6)$ \\
\hline & Unmarried & 474 & $67.9(64.4-71.3)$ \\
\hline & Employed & 325 & $46.6(42.9-50.3)$ \\
\hline \multirow[t]{2}{*}{ Employment Status } & Unemployed & 294 & $42.1(38.5-45.8)$ \\
\hline & Daily Laborer & 79 & $11.3(9.2-13.9)$ \\
\hline \multirow[t]{2}{*}{ Current Smoking History } & Smoker & 60 & $8.6(6.7-10.9)$ \\
\hline & None Smoker & 638 & $91.4(89.1-93.3)$ \\
\hline \multirow[t]{2}{*}{ TB Treatment History } & New & 527 & $75.5(72.2-78.5)$ \\
\hline & Previously Treated & 171 & $24.5(21.5-27.8)$ \\
\hline \multirow[t]{2}{*}{ TB type } & $\begin{array}{l}\text { PTB }^{\dagger} \\
\text { EPTB }^{\ddagger}\end{array}$ & $\begin{array}{l}416 \\
215\end{array}$ & $\begin{array}{l}59.6(55.9-63.2) \\
30.8(27.5-34.3)\end{array}$ \\
\hline & MDR-TB ${ }^{\S}$ & 67 & $9.6(7.6-12.0)$ \\
\hline \multirow[t]{2}{*}{ HIV Sero-status } & None Reactive & 548 & $78.5(75.3-81.4)$ \\
\hline & Reactive & 150 & $21.5(18.6-24.7)$ \\
\hline \multirow[t]{2}{*}{ ART $^{*}$ Status } & Not on ART & 581 & $83.2(80.3-85.8)$ \\
\hline & On ART & 117 & $16.8(14.2-19.7)$ \\
\hline Alcohol Use Disorder Risk & $\begin{array}{l}\text { There is Risk } \\
\text { No Risk }\end{array}$ & $\begin{array}{l}105 \\
593\end{array}$ & $\begin{array}{l}15.0(12.6-17.9) \\
85.0(82.1-87.4)\end{array}$ \\
\hline \multirow[t]{2}{*}{ Psychological Distress Symptom } & No Symptom & 357 & $51.1(47.4-54.8)$ \\
\hline & There is Symptom & 341 & $48.9(45.2-52.6)$ \\
\hline
\end{tabular}

*ART-Antiretroviral Therapy, $\nsucc$ PTB-Pulmonary TB,, FPTB-Extra Pulmonary TB, $\$ M D R$-TB-Multidrug Resistant TB

DOI: http://dx.doi.org/10.4314/ejhs.v27i5.2 
Table 3 depicts proportions of non-adherence with respect to study participants' characteristics. A total of $136(19.5 \%)$ participants were nonadherent. Of the total non-adherent participants, males were slightly more, 73(53.7), than females $63(46.3 \%)$. Participants in the age group of less than 35 years were more non-adherent, 91(66.9\%), compared to other age groups. Similarly, large proportions of non-adherent participants were unmarried $(70.6 \%)$, elementary school and below, $(60.3 \%)$, at low socioeconomic status, $(61.8 \%)$, newly started TB treatment, (70\%), and pulmonary TB patients, $(64.7 \%)$.

Knowledge and perception regarding TB disease and its treatment: The mean knowledge score of the participants was $30.5( \pm 4.7)$, and $59.0 \%$ of them were scored more than mean score of knowledge. Among non-adherent participants, 92(67.7\%) scored less than the mean knowledge score. The mean perceived susceptibility and perceived severity scores were $28.2(\mathrm{SD}=6.6)$ and $36.9(\mathrm{SD}=5.0)$ respectively. Similarly, the mean score of perceived barrier was $65.5(\mathrm{SD}=$ 16.6) and the mean score of perceived benefit was $32.8(\mathrm{SD}=4.1)$. Moreover, the mean score of cue to action and perceived self-efficacy were $31.7(\mathrm{SD}=5.3)$ and $51.5(\mathrm{SD}=5.6)$ respectively (Table 3).

Alcohol use and tobacco smoking: The mean alcohol use disorder score on WHO 10 items AUDIT was $3.5(\mathrm{SD}=2.7)$. Using WHO AUDIT cut-off point (greater than 8 total score) $111(15.0 \%)$ of the participants fulfilled hazardous and harmful alcohol use as well as possible alcohol dependence. Out of the total nonadherence, (19.5\%), 42(28\%) of the participants had alcohol use disorder symptoms. More than $90 \%$ of the participants were non-smoker, and of the total (60) smokers, 14(23.3\%) participants were non-adherent, while slightly lower $(19.1 \%)$ were non-adherent from non-smokers.
Psychological distress: The mean score of psychological distress was $18.7(\mathrm{SD}=7.8)$ on $\mathrm{K}$ 10 items. Slightly less than half $(48.9 \%)$ of the participant met the criteria for psychological distress on cut-off point of 15 score. Of $136(19.5 \%)$ the total non-adherence, $76(27.4 \%)$ showed symptoms of psychological distress.

Bivariate analysis: On Bivariate analysis (Table 4), high school completion (Crude Odds Ratio $(C O R)=2.17$, 95\% Confidence Interval (CI), (1.06-4.46)), being on ART $(C O R=1.73, \quad 95 \% \quad C I \quad(1.09-2.73))$, availability of AUD $(C O R=2.06,95 \% C I$ (1.29-3.29)), high economic status $(C O R=$ 0.52 , 95\% CI (0.35-0.76)), perceived barriers $(C O R=1.35,95 \% \quad C I \quad(1.35-1.16))$ and psychological distress $(C O R=1.65,95 \% C I$ (1.45-2.00) were significantly associated with TB treatment non-adherence.

Multivariate analysis: The final multivariable logistic regression model contains five independent variables (ART status, TB treatment history, educational status, economic status, knowledge level), and six HBM domains indicated a high goodness of fit with the data $(\chi 2=70.07$, $\mathrm{p}<0.001)$, demonstrating that the model was able to differentiate between participants who were adherent and non-adherent. The final multivariable logistic regression analysis revealed that, being on ART (Adjusted Odds Ratio $($ AOR $)=1.79,95 \%$ $C I$ (1.09-2.95)), AUD $(A O R=2.11,95 \% C I$ (1.33-3.37)), high economic status $(A O R=0.53$, 95\% CI (0.33-0. 82)), perceived barrier $(A O R=$ 1.21, 95\% CI (1.10-1.47)) and psychological distress $(A O R=1.83,95 \% C I(1.47-2.29))$ were independently associated with treatment nonadherence (Table 4). 
Table 3: Participant characteristics distribution of TB treatment non-adherence

\begin{tabular}{|c|c|c|c|c|c|}
\hline \multirow[t]{2}{*}{ Characteristics } & & \multicolumn{3}{|c|}{ Adherence } & \multirow[b]{2}{*}{$\%(95 \% \mathrm{CI})$} \\
\hline & & Adherent & $\%(95 \% \mathrm{CI})$ & Non-Adherent & \\
\hline \multirow[t]{3}{*}{ Gender } & Female & 234 & $41.6(37.6-45.8)$ & 63 & $46.3(38.2-54.7)$ \\
\hline & Male & 328 & $58.4(54.2-62.4)$ & 73 & $53.7(45.3-61.8)$ \\
\hline & $18-24$ & 160 & $28.5(24.9-32.3)$ & 33 & $24.3(17.8-32.2)$ \\
\hline \multirow[t]{3}{*}{ Age Group } & $25-34$ & 206 & $36.7(32.8-40.7)$ & 58 & $42.6(34.7-51.1)$ \\
\hline & $35-44$ & 111 & $19.8(16.7-23.3)$ & 25 & $18.4(12.7-25.8)$ \\
\hline & $45 \&$ Above & 84 & $14.9(12.2-18.1)$ & 20 & $14.7(9.7-21.7)$ \\
\hline \multirow[t]{3}{*}{ Marital Status } & Married & 184 & $32.7(29.0-36.7)$ & 40 & $29.4(22.4-37.6)$ \\
\hline & Unmarried & 378 & $67.3(63.3-71.0)$ & 96 & $70.6(62.4-77.6)$ \\
\hline & Employed & 271 & $48.2(44.1-52.4)$ & 54 & $39.7(31.9-48.1)$ \\
\hline Employment & Unemployed & 229 & $40.7(36.8-44.9)$ & 65 & $47.8(39.6-56.1)$ \\
\hline \multirow[t]{2}{*}{ Status } & Daily Laborer & 62 & $11.0(8.7-13.9)$ & 17 & $12.5(7.9-19.2)$ \\
\hline & Elementary \& less & 308 & $54.8(50.7-58.9)$ & 82 & $60.3(51.9-68.1)$ \\
\hline Educational & High School & 179 & $31.9(28.1-35.8)$ & 45 & $33.1(25.7-41.4)$ \\
\hline Status & Diploma \& above & 75 & $13.3(10.8-16.4)$ & 9 & $6.6(3.4-12.3)$ \\
\hline \multirow[t]{3}{*}{ Economic Status } & Low & 233 & $41.5(37.5-45.6)$ & 84 & $61.8(53.4-69.5)$ \\
\hline & Medium & 146 & $26.0(22.5-29.8)$ & 34 & $25.0(18.5-32.9)$ \\
\hline & High & 183 & $32.6(28.8-36.6)$ & 18 & $13.2(8.5-20.0)$ \\
\hline Current Smoking & Smoker & 46 & $8.2(6.2-10.8)$ & 14 & $10.3(6.1-16.7)$ \\
\hline History & None Smoker & 516 & $91.8(89.2-93.8)$ & 122 & $89.7(83.4-93.9)$ \\
\hline TB Treatment & New & 433 & $77.0(73.4-80.3)$ & 94 & $69.1(60.9-76.3)$ \\
\hline \multirow[t]{2}{*}{ History } & Previously Treated & 129 & $23.0(19.7-26.6)$ & 42 & $30.9(23.7-39.1)$ \\
\hline & $\mathrm{PTB}^{\dagger}$ & 328 & $58.4(54.2-62.4)$ & 88 & $64.7(56.4-72.2)$ \\
\hline \multirow[t]{2}{*}{ TB type } & ЕРTB & 181 & $32.2(28.3-36.2)$ & 34 & $25.0(18.5-32.9)$ \\
\hline & MDR-TB ${ }^{\S}$ & 53 & $9.4(7.3-12.2)$ & 14 & $10.3(6.1-16.6)$ \\
\hline \multirow[t]{2}{*}{ HIV Sero Status } & None Reactive & 444 & $79.0(75.4-82.2)$ & 104 & $76.5(68.6-82.9)$ \\
\hline & Reactive & 118 & $21.0(17.8-24.6)$ & 32 & $23.5(17.2-31.4)$ \\
\hline \multirow[t]{2}{*}{ ART Status* } & On ART & 80 & $14.2(11.6-17.4)$ & 32 & $23.5(17.2-31.4)$ \\
\hline & Not on ART & 477 & $84.9(81.7-87.6)$ & 104 & $76.5(68.4-82.9)$ \\
\hline \multirow[t]{2}{*}{$\mathrm{AUD}^{\mathbb{I}}$} & No Risk & 489 & $87.0(84.0-89.6)$ & 104 & $76.5(68.4-82.9)$ \\
\hline & There is Risk & 73 & $13.0(10.5-16.0)$ & 32 & $23.5(17.2-31.4)$ \\
\hline \multirow[t]{2}{*}{$\mathrm{PDS}^{* *}$} & No Symptom & 293 & $52.1(48.0-56.2)$ & 64 & $47.1(38.9-55.4)$ \\
\hline & There is Symptom & 269 & $47.9(43.8-52.0)$ & 72 & $52.9(44.6-61.1)$ \\
\hline
\end{tabular}

*ART-Antiretroviral Therapy, $†$ PTB-Pulmonary TB, $\neq$ EPTB-Extra Pulmonary TB, $\$ M D R$-TB-Multidrug Resistant TB, ${ }^{\mathbb{q}} A U D$ Alcohol Use Disorder, ${ }^{* *} P D S$-Psychological distress symptom 
Table 4: Predictors of TB treatment non-adherence

\begin{tabular}{|c|c|c|c|c|c|}
\hline Characteristics & & Crud OR (95\% CI) & P-Value & Adjusted OR (95\% CI) & P-Value \\
\hline \multirow[t]{2}{*}{ Gender } & Female & 1.00 & & & \\
\hline & Male & $0.83(0.57-1.21)$ & 0.335 & & \\
\hline \multirow[t]{3}{*}{ Marital Status } & Married & 1.00 & 0.476 & & \\
\hline & Unmarried & $1.17(0.78-1.76)$ & & & \\
\hline & Diploma \& & 1.00 & & & \\
\hline \multirow[t]{2}{*}{ Educational Status } & Above & & & & \\
\hline & $\begin{array}{l}\text { High School } \\
\& \text { Less }\end{array}$ & $2.17(1.06-4.46)$ & 0.053 & $2.1(0.99-4.52)$ & 0.053 \\
\hline \multirow[t]{2}{*}{ Current Smoking History } & Non-smoking & 1.00 & & & \\
\hline & Smoker & $1.29(0.69-2.42)$ & 0.495 & & \\
\hline \multirow[t]{2}{*}{ TB Treatment History } & New & 1.00 & & & \\
\hline & $\begin{array}{l}\text { Previously } \\
\text { Treated }\end{array}$ & $1.50(1.00-2.27)$ & 0.059 & $1.43(0.90-2.25)$ & 0.128 \\
\hline \multirow[t]{2}{*}{ TВ Type } & ЕРТВ & 1.00 & & & \\
\hline & $\mathrm{PTB}^{\dagger}$ & $1.43(0.93-2.18)$ & 0.267 & & \\
\hline \multirow[t]{3}{*}{ HIV Sero-status } & None & 1.00 & & & \\
\hline & Reactive & & & & \\
\hline & Reactive & $0.86(0.55-1.35)$ & 0.561 & & \\
\hline \multirow[t]{2}{*}{ ART $^{*}$ Status } & Not on ART & 1.00 & & & \\
\hline & On ART & $1.73(1.09-2.73)$ & 0.022 & $1.79(1.09-2.95)$ & 0.023 \\
\hline \multirow[t]{2}{*}{ AUDR $^{\text {II }}$} & No Risk & & & & \\
\hline & There is Risk & $2.06(1.29-3.29)$ & 0.001 & $2.11(1.33-3.37)$ & 0.002 \\
\hline Age (in year) & & $1.00(0.99-1.02)$ & 0.843 & & \\
\hline $\begin{array}{l}\text { Economic Status } \\
\text { Psychological Distress }\end{array}$ & & $\begin{array}{l}0.52(0.35-0.76) \\
1.65(1.45-2.00)\end{array}$ & $\begin{array}{l}0.001 \\
<0.001\end{array}$ & $\begin{array}{c}0.53(0.33-0.82) \\
1.83(1.47-2.29)\end{array}$ & $\begin{array}{r}0.004 \\
<0.001\end{array}$ \\
\hline Knowledge & & $0.99(0.96-1.03)$ & 0.763 & $0.98(0.96-1.05)$ & 0.841 \\
\hline Perceived Susceptibility & & $0.81(0.67-1.00)$ & 0.051 & $0.81(0.62-1.05)$ & 0.106 \\
\hline Perceived Severity & & $0.80(0.68-0.95)$ & 0.078 & $0.95(0.73-1.23)$ & 0.678 \\
\hline Perceived Barrier & & 1. 35(1.16-1.57) & $<0.001$ & $1.21(1.10-1.47)$ & 0.014 \\
\hline Perceived Benefit & & $0.81(0.78-1.21)$ & 0.059 & $0.89(0.69-1.15)$ & 0.243 \\
\hline Cue to Action & & $0.82(0.70-0.97)$ & 0.019 & $0.85(0.67-1.10)$ & 0.203 \\
\hline Perceived Self-efficacy & & $0.88(0.78-0.99)$ & 0.034 & $0.98(0.77-1.17)$ & 0.224 \\
\hline
\end{tabular}

*ART-Antiretroviral Therapy, $†$ PTB-Pulmonary TB, $\neq$ EPTB-Extra Pulmonary TB, ${ }^{\pi} A U D$-Alcohol Use

\section{DISCUSSION}

For successful treatment outcome, optimal treatment adherence is mandatory. According to
WHO, to be adherent, patient should attend the scheduled visit and take regular medication above $90 \%$ of prescribed doses (4). However, evidences show that, a considerable number of TB

DOI: http://dx.doi.org/10.4314/ejhs.v27i5.2 
patients are interrupting their treatment due to various and interrelated psychological (10,11), socio- economic $(11,12,16,17,21,43)$, behavioral (18-20), health care system (22) and health care workers related factors $(13,14,23)$.

In this study, the proportion of treatment non-adherence was found to be higher than studies recently reported from Ethiopia (14,27). Multivariable logistic regression analysis revealed that ART status, alcohol use, economic status, perceived barrier and psychological distress were able to independently predict TB treatment nonadherence.

The overall non-adherence proportion of our study was nearly comparable with a previous study reported from Ethiopia (13). However, it was higher than other recently reported studies from the country $(14,27)$. This difference on nonadherence level is most probably due to differences in adherence measurement techniques used and study population addressed. Study populations of both studies $(14,27)$ were rural and urban mixed populations; however, our study population was urban dwellers. In addition, about $29.3 \%$ of the participants studied were immigrants from rural part of Addis Ababa before six months, and of these, $18.1 \%$ were daily laborers who were struggling to fulfill their daily living. These participants may easily enter into treatment interruption because of hard living situations and even they might have gone back to their original places abandoning the treatment to seek support from family as previous study reported (15). Moreover, a study conducted by Sendagire et al. (26) reported that urban movement and alcohol consumption had significant associations with loss to follow-up among urban population. Regarding non-adherence measurement technique, a study reported by Adane et al. (27) used pills counting technique and study reported by Kiros et al. (14) used VAS, but health care workers were used to estimate non- adherence level of patients. However, in our study, we used VAS and nonadherence level was estimated by individual patient themselves, being supported by health care workers. Hence, we assume that this nonadherence proportion differences occurred most probably due to these factors (non-adherence measurement techniques).

Previous studies reported from Ethiopia $(12,13)$ demonstrated that being on dual treatment (on TB and HIV treatment) and pills burden were the most significant barriers of TB treatment adherence. This result was consistent with our findings, i.e. TB patients on dual treatment (anti TB and ART) were 1.82 times more non-adherent than those who were not on dual treatment.

Economic hardship is the highest determinant of treatment non-adherence. According to previous studies, TB patients who have financial limitation are more likely to be in devastating situation from lack of transportation cost and living costs which are important to regular treatment follow-up (12,16,17,21). Furthermore, poverty is one of the major barrier to healthy behavior practice like strictly following treatment, and it could easily put patients into risky behaviors such as tobacco smoking and alcohol misuse due to lack of enabling environment. Thus, being poor and practicing risky behaviors such as alcohol consumption and tobacco smoking would likely lead to poor health outcomes as the consequence of treatment nonadherence (21). Our study also revealed a similar result, and TB patients who were at high economic score were $31 \%$ times likely to be non-adherent than participants who were at low economic score.

Naidoo et al. (21) and Sendagire et al. (26) reported that AUD risk was strongly associated with TB treatment non-adherence. The results of these studies were in agreement with our finding, and TB patients who were at AUD on WHO AUDIT 10- items were 1.89 times likely to be non-adherent than those who were not at AUD. This may be due to the fact that TB patients who drink alcohol may miss their medication to drink alcohol with friends and may miss their treatment due to memory and decision impairment related to alcohol. Moreover, according to a study reported from Uganda (23), as most TB patients who dirk alcohol are residing in slam areas and tend to give wrong addresses, they would be easily lost to

DOI: http://dx.doi.org/10.4314/ejhs.v27i5.2 
follow-up and could not be traced back after interrupting their treatment.

Perceived tangible (social, economic, health care system and health care worker factors) and individual belief about TB disease and its treatment barriers were associated with $\mathrm{TB}$ treatment non-adherence. This result was alongside with the study reported by Llongo (31), which showed the impact of a patient's incongruent belief on treatment adherence based on HBM. In addition, our finding was consistent with previous studies that showed the effect of tangible barriers on treatment adherence without applying HBM (18-21).

According to a study reported by Prince et al. (44) and a systematic review reported by Pachi et al (10), the association between mental illness and other co-morbidities contributes to TB treatment non-adherence. These study findings were consistent with our finding in which TB patients who had psychological distress symptoms were 1.83 time more at risk of non-adherent than those who had no symptoms.

The study questionnaire was administered by health care worker at the TB clinic of the selected study areas. Thus, health care workers could have overestimated the adherence level of patients to demonstrate their work performance. This could be the main limitation of this study. On the other hand, TB patients themselves may not give their own exact perception particularly related to health care workers and health care facilities, as the questionnaire was administered by health care works themselves. This may lead to under reporting of tangible barriers that are related to health care workers behaviors and health care facilities' services.

Despite these limitations, we conclude that non-adherence level was $19.5 \%$ among TB patients on treatment. ART status, economic status, AUD, perceived barriers and psychological distress were significantly associated with $\mathrm{TB}$ treatment non-adherence. Thus, implementation of comprehensive interventions, focusing on poverty, AUD, perceived barriers to treatment and psychological counseling are important to enhance TB treatment adherence.

\section{ACKNOWLEDGEMENT}

The authors acknowledge the contribution of KNCV/USAID TBCARE-I and Ethiopian Public Health Institute for funding this study. Also, the authors extend their gratitude to Tehran University of Medical Sciences-International Campus for awarding the diamond scholarship for first author.

\section{REFERENCES}

1. Hall RG, Leff RD, Gumbo T. Treatment of active pulmonary tuberculosis in adults: current standards and recent advances. Insights from the Society of Infectious Diseases Pharmacists. Pharmacotherapy. 2009;29(12):1468-81.

2. Bastakoti S, Khanal S, Dahal B, Pun NT. Treatments: Focus on Pharmacy Practice in Nepal. JCDR. 2013;7(4):754-7.

3. Hirpa S, Medhin G, Girma B, Melese M, Mekonen A, Suarez P. Determinants of multidrug-resistant tuberculosis in patients who underwent first-line treatment in Addis Ababa: a case control study. BMC Public Health; 2013;13(1):1.

4. WHO. Adherence to long-term therapies: Evidence for action. WHO Press. Geneva, Switzeland; 2003.

5. WHO. Global Tuberculosis Report, WHO report. Geneva, Switzerland; 2014 p. 8.

6. Pettit AC, Cummins J, Kaltenbach LA, Sterling TR, Warkentin JV. Non-adherence and drug-related interruptions are risk factors for delays in completion of treatment for tuberculosis. Int $J$ Tuberc Lung Dis. 2013;17(4):486-92.

7. Boogaard Jossy Van Den, Boeree Martin J, Kibiki Gibson S, Aarnoutse RE. The complexity of the adherence-response relationship in tuberculosis treatment: why are we still in the dark and how can we get out ? TMIH; 2011;16(6):693-8.

8. Payero MÁ, Castro NML De, Samartín MU, Vila AM, López CV, Piñeiro G. Medication non- adherence as a cause of hospital admissions. Farm Hosp. 2014;38(4):328-33. 
9. Munro S, Lewin S, Smith H, Engel M, Atle F, Volmink J. Patient adherence to tuberculosis treatment: a systematic review of qualitative research. PLoS Med. 2007;4(Suppl 7):e238.

10. Pachi A, Bratis D, Moussas G, Tselebis A. Psychiatric Morbidity and Other Factors Affecting Treatment Adherence in Pulmonary Tuberculosis Patients. Tube Res Treat. 2013;2013:37.

11. Jakubowiak WM, Bogorodskaya EM, Borisov SE, Danilova ID, Lomakina OB, Kourbatova EV. Impact of socio-psychological factors on treatment adherence of TB patients in Russia. Tuberc. 2008;88(5):495-502.

12. Gebremariam MK, Bjune GA, Frich JC. Barriers and facilitators of adherence to TB treatment in patients on concomitant TB and HIV treatment: a qualitative study. $B M C$ Public Health; 2010;10(1):651.

13. Kebede A, Wabe TN. Medication Adherence and its Determinants among Patients on Concomitant Tuberculosis and Antiretroviral Therapy in South West Ethiopia. N Am J Med Sci. 2012;4(2):67-71.

14. Kiros YK, Teklu T, Desalegn F, Tesfay M, Klinkenberg E, Mulugeta A. Adherence to anti-tuberculosis treatment in Tigray, Northern Ethiopia. PHA. 2014;4(4):S31-6.

15. Sagbakken M, Frich JC, Bjune G. Barriers and enablers in the management of tuberculosis treatment in Addis Ababa , Ethiopia: a qualitative study. BMC Public Health. 2008;11:1-11.

16. Muture BN, Keraka MN, Kimuu PK, Kabiru EW, Ombeka VO, Oguya F. Factors associated with default from treatment among tuberculosis patients in nairobi province, Kenya: A case control study. BMC Public Health; 2011;11(1):696.

17. Maruza M, Fp M, Albuquerque M, Coimbra I, Moura LV, Montarroyos UR, et al. Risk factors for default from tuberculosis treatment in HIV-infected individuals in the state of Pernambuco , Brazil: a prospective cohort study. BMC Infect Dis; 2011;11(1):351.

18. DiMatteo MR, Haskard KB, Williams SL. Health beliefs, disease severity, and patient adherence: a meta-analysis. Med Care. 2007;45(6):521-8.

19. Cramm JM, Finkenflügel HJM, Møller V, Nieboer AP. TB treatment initiation and adherence in a South African community influenced more by perceptions than by knowledge of tuberculosis. BMC Public Health; 2010;10:72.

20. Horne R, Chapman SCE, Parham R, Freemantle N, Forbes A, Cooper V. Understanding Patients' Adherence-Related Beliefs about Medicines Prescribed for LongTerm Conditions: A Meta-Analytic Review of the Necessity-Concerns Framework. PLoS One. 2013;8(12):e80633.

21. Naidoo P, Peltzer K, Louw J, Matseke G, Mchunu G, Tutshana B. Predictors of tuberculosis ( TB ) and antiretroviral ( ARV) medication non-adherence in public primary care patients in South Africa: a cross sectional study. BMC Public Health; 2013;13:396.

22. Tadesse T, Demissie M, Berhane Y, Kebede Y, Abebe M. Long distance travelling and financial burdens discourage tuberculosis DOTs treatment initiation and compliance in Ethiopia: a qualitative study. $B M C$ PublicHealth; 2013;

23. Elbireer S, Guwatudde D, Mudiope P, Nabbuye-sekandi J, Manabe YC. Tuberculosis treatment default among HIV-TB co-infected patients in urban Uganda. Trop Medand Int Heal. 2011;16(8):981-7.

24. Peltzer K, Louw J, Mchunu G, Naidoo P, Matseke G, Tutshana B. Hazardous and Harmful Alcohol Use and Associated Factors in Tuberculosis Public Primary Care Patients in South Africa. Int J Env Res Public Heal. 2012;9(9):3245-57.

25. Lavigne M, Rocher I, Steensma C, Brassard P. The impact of smoking on adherence to treatment for latent tuberculosis infection. BMC Public Health; 2006;6:66.

26. Sendagire I, Schim Van der Loeff $M$, Kambugu A, Konde-Lule J, Cobelens F. Urban Movement and Alcohol Intake Strongly Predict Defaulting from Tuberculosis 
Treatment: An Operational Study. PLoS One; 2012;7(5):e35908.

27. Adane AA, Alene KA, Koye DN, Zeleke BM. Non-adherence to anti-tuberculosis treatment and determinant factors among patients with tuberculosis in northwest Ethiopia. PLOS One;8(11):e78791.

28. Glanz K, Bishop DB. The Role of Behavioral Science Theory in Development and Implementation of Public Health Interventions. Annu Rev Public Heal. 2010;13:399-418.

29. Glanz K, Rimer BK, Viswanath K. Health Behavior and Health Education: Theory, Research, and Practice 4th ed. Published by Jossey-Bass, USA, San Francisco; 2008.

30. Poss J. The meaning of tuberculosis for Mexican immigrant farm workers in the United States. Soc Sci Med. 1998;47:95-202.

31. Llongo I. Tuberculosis health belief gaps of tuberculosis and suspected tuberculosis cases in New York City. Int J Clin Heal Psychol. 2004;4(1):69-90.

32. Barnhoon NF, Adriaanse H. In search of factors responsible for non-compliance among tuberculosis patients in Wardha district, India. Soc Sci Med. 1992;34:291-306.

33. Ethiopian Central Statistical Agency (CSA. Population and Housing Census ReportCountry - 2010, English [eng], Ethiopia [eth] Publisher(s): Central Statistical Agency, Addis Ababa, Ethiopia. Addis Ababa, Ethiopia and Calverton, Maryland, USA: Central Statistical Agency and ICF International; 2010.

34. Ethiopian Federal Minster of Health. Health and Health Related Indicators, Addis Ababa, Ethiopia. Addis Ababa, Ethiopia; 2012 p. 2942.

35. Ethiopian Federal Minster of Health. Guidelines for Clinical and Programmatic Management of TB, TB/HIV and Leprosy in Ethiopia. 2013 p. 9-154.

36. WHO, Department of Immunization V and B. Training for mid-level managers (MLM): 7. The EPI coverage survey. Geneva, Switzerland; 2008.
37. Kessler R, Andrews G, Colpe LJ, Hiripi E, Mroczek DK, Normand S-TL et al. Short screening scales to monitor population prevalence and trends in nonspecific psychological distress. Psychol Med. 2002;32:959.

38. Kessler RC, Barker PR, Colpe LJ, Epstein JF, Gfroerer JC, Hiripi E et. a. Screening for serious mental illness in the general population. Arch Gen Psychiatry. 2003;60(2):184.

39. Peltzer K, Naidoo P, Matseke G, Louw J, Mchunu G, Tutshana B. Prevalence of psychological distress and associated factors in tuberculosis patients in public primary care clinics in South Africa. BMC Psychiatry. 2012;12:89.

40. Deribew A, Tesfaye M, Hailmichael Y, Apers L, Abebe G, Duchateau L, et al. Common mental disorders in TB/HIV co-infected patients in Ethiopia. BMC Infect Dis. 2010;10:201.

41. Saunders JB, Aasland OG, Amundsen A, Grant M. Alcohol consumption and related problems among primary health care patients: WHO collaborative project on early detection of persons with harmful alcohol consumption. Addiction. 1993;88(3):349-62.

42. Government of Western Australian Department of Health. Mental Health Smoking Assessment Check list. HP012591 JAN'13. 2013;

43. 43.Hargreaves JR, Boccia D, Evans CA, Adato M, Petticrew M, Porter JDH. The Social Determinants of Tuberculosis: From Evidence to Action, Framing Health Matters. Am J Public Heal. 2011;101(4):654-62.

44. Prince M, Patel V, Saxena S, Maj M, Maselko J, Philips MR. No health without mental health. Lancet. 2007;370(9590):85977 . 